\title{
Induced transcriptional profiling of phenylpropanoid pathway genes increased flavonoid and lignin content in Arabidopsis leaves in response to microbial products
}

\author{
Mohammad Babar Ali ${ }^{*}$ and David H McNear Jr
}

\begin{abstract}
Background: The production and use of biologically derived soil additives is one of the fastest growing sectors of the fertilizer industry. These products have been shown to improve crop yields while at the same time reducing fertilizer inputs to and nutrient loss from cropland. The mechanisms driving the changes in primary productivity and soil processes are poorly understood and little is known about changes in secondary productivity associated with the use of microbial products. Here we investigate secondary metabolic responses to a biologically derived soil additive by monitoring changes in the phenlypropanoid (PP) pathway in Arabidopsis thaliana.
\end{abstract}

Results: This study was designed to test the influence of one of these products (Soil Builder ${ }^{\mathrm{TM}}$-AF, SB) on secondary metabolism after being applied at different times. One time (TI) application of SB to Arabidopsis increased the accumulation of flavonoids compared to multiple (TII) applications of the same products. Fourteen phenolic compounds including flavonols and anothocyanins were identified by mass spectrometry. Kaempferol-3,7-O-bis-aL-rhamnoside and quercetin 3,7-dirhamnoside, the major compounds, increased 3-fold and 4-fold, respectively compared to control in the TI treatment. The most abundant anthocyanin was cyanidin 3-rhamnoglucoside, which increased 3-fold and 2-fold in TI compared to the control and TII, respectively. Simultaneously, the expression of genes coding for key enzymes in the PP pathway (phenylalanine ammonia lyase, cinnamate 4-hydroxylase, chalcone synthase, flavonoid-3'-O-hydroxylase, flavonol synthase1 and dihydroflavonol-4-reductase) and regulatory genes (production of anthocyanin pigment2, MYB12, MYB113, MYB114, EGL3, and TT8) were up-regulated in both treatments (TI and TII). Furthermore, application of TI and TII induced expression of the lignin pathway genes (hydroxyl cinamyl transferase, caffeyl-COA O-methyl transferase, cinnamyl alcohol dehydrogenase, cinnamyl-CoA reductase, secondary wall-associated NAC domain protein1, MYB58 and MYB63 resulting in higher accumulation of lignin content compared to the control.

Conclusions: These results indicate that the additions of microbially based soil additives have a perceptible influence on phenylpropanoid pathway gene regulation and its production of secondary metabolites. These findings open an avenue of research to investigate the mode of action of microbially-based soil additives which may assist in the sustainable production of food, feed, fuel and fiber.

Keywords: Arabidopsis, Metabolites, Microbes, Transcriptional profiling, Plant Growth Promoting Rhizobacteria, Soil Builder

\footnotetext{
* Correspondence: mohammad.ali2@uky.edu

Department of Plant and Soil Sciences, Rhizosphere Science Laboratory,

University of Kentucky, Lexington, KY 40546, USA
} 


\section{Background}

One of major challenges in the $21^{\text {st }}$ century is the sustainable production of food, fuel and fiber crops with enhanced functional and nutritive value (e.g. flavonoids and anthocyanins) to meet the demands of an everincreasing global population $[1,2]$. To meet this demand requires the development of alternative more sustainable methods for the production and enhancement of value added agricultural commodities in a way that will have minimal impact on the ecosystem. Current agricultural practices are largely based on the use of chemical fertilizers and synthetic pesticides for improved crop growth and yield. However, our dependence and overuse of these fertilizers has resulted in contamination of soil, ground and surface waters. Increasing demand for healthier and more nutrient-dense foods by more health-conscious consumers and an improved environmental awareness has resulted in an increased interest in and a rapid change towards ecofriendly sustainable agricultural farming systems.

One component of this new sustainable production system is the use of microbe-based fertilizers (i.e. biostimulants) containing potential beneficial strains of microorganism and their metabolites many of which have an important role in conditioning the rhizosphere for improved plant growth and nutrient use efficiency $[3,4]$. Since the 1970's we have been cognizant of the potential benefits on plant growth of specialized plant growth promoting rhizobacteria (PGPR) [5]. There have been many reports on improvements in plant defense, health and growth, resistance to pathogens, enhanced salt tolerance, and improved nutrient uptake in response to PGPR [6,7] that could have led to the development of novel agricultural applications. In spite of all these advantages, the use of microbial-based products has not been effectively exploited at larger scales to improve plant yields and most certainly not as a means to selectively enhance gene expression and production of beneficial secondary metabolite in crops.

Phenylpropanoids are a large group of polyphenolic compounds that comprise an important class of secondary metabolites such as flavonoids, anthocyanin and lignin in plants [8]. Phenylpropanoids have important functions in flower coloration, pollinator attraction, protection from ultraviolet (UV) light, as signaling molecules between plants and microbes, and as antioxidants [9]. Additionally, when consumed by humans phenylpropanoids offer a myriad of health benefits $[10,11]$. There have been many studies on the biosynthesis of flavonols and the PP pathway in general via metabolic engineering targeting important agronomic traits such as the production of novel colors and color patterns in ornamentals $[8,12]$. Many phenylpropanoids act as inducers of plantmicrobe symbioses [13], whereas others exhibit broadspectrum antimicrobial activity and are therefore believed to help plants fight microbial diseases [14]. In addition, several studies have examined how the PP and defense related pathways are regulated by interactions between soil microorganisms and plant roots [15-18]. The genes involved in PP pathway such as chalcone synthase (CHS), chalcone isomerase (CHI), flavanone 3-hydroxylase (F3H), flavonoid 3'-hydroxylase (F3'H), and flavonol synthase1 (FLS1) play important roles in the production of secondary metabolites, while dihydroflavonol 4-reductase (DFR), and leucoanthocyanidin dioxygenase (LDOX) are involved in the production of colored anthocyanidins (Additional file 1). After production, these products are further modified by glycosylation, acylation, and methylation in a complex process that changes their stability, solubility, or localization, and thereby the biological properties of the conjugated molecules [19].

The transcription factors regulating the expression of these structural genes have been well characterized in plant species including Arabidopsis [20]. MYB11, MYB12, and MYB111 encode three functionally redundant $M Y B \mathrm{~s}$ regulating the expression of several 'early' flavonoid biosynthetic genes [21]. On the other hand, TFs such as PAP1, $P A P 2, G L 3, T T 8$ and TTG1 which are components of the $M Y B / b H L H / W D R(M B W)$ transcriptional complexes mediate the 'late' anthocyanin biosynthesis genes [21,22]. The lignin biosynthesis pathway is well-characterized and plays an important role in plant growth, development, increase cell wall integrity, facilitating water transport and providing resistance against pathogen [23-25]. The genes which are involved in lignin biosynthesis are largely regulated at the transcription level and lignin-specific transcription factor MYB58, MYB63 and SND1 can induce the biosynthetic pathways for the synthesis of lignin [26,27].

To date there is little research aimed at understanding the influence of microbial products on plant secondary metabolism making it difficult to assess a potential functional relationship(s). Understanding how phenylpropanoid metabolism changes in response to microbes or microbial-based products will help to improve our fundamental understanding of plant biology, and would be useful for the development of natural products aimed at improving crop yield and quality. Preliminary analysis of the product composition shows that it is composed of PGPR related bacteria and use of the product can result in plant growth promotion $[28,29]$. We hypothesized that microbial-based products, known to improve plant growth and nutrient uptake, can induce the PP pathway and lignin pathway in Arabidopsis. Therefore, this study was designed to evaluate how application and the timing of application (single and multiple times) influence the PP pathway in Arabidopsis. Quantitative real-time PCR (qRT-PCR) was used in this study for transcriptional profiling of flavonoid and lignin pathway genes, and high performance liquid chromatography (HPLC) and liquid chromatography- 
electrospray ionization-quadrupole-time of flight-mass spectrometry (LC/ESI-Q-TOFMS/MS) were used to determine flavonoid content. The results show that application of microbial products induced the PP pathway and there was a different response dependent on application timing. In both cases application of the microbial product induced flavonoid and lignin content in Arabidopsis leaves compared to an untreated control.

\section{Results}

\section{Metabolite composition}

Fourteen flavonoids were identified by HPLC-QTOFMS/MS analysis in the leaves of Arabidopsis (Figures 1 and 2), including nine flavonols: kaempferol-3,7-Obis-alpha-L-rhamnoside (F1), kaempferol-3-O-alphaL-rhamnopyranosyl (1-2)-beta-D-glucopyranoside-7-O-alphaL-rhamnopyranoside (F2), kaempferol with rhamnoside (F3), kaempferol with rhamnoside (F4), kaempferol with rhamnoside (F5), kaempferol in hydrolyzed form (F6), quercetin 3,7-dirhamnoside (F7), apigenin7-(2",3"-diacetylglucoside), (F8), and pentamethoxydihydroxy flavone (F9); as well as five representative anthocyanidins (cyanidin 3-rhamnoglucoside (A1), (cyanidin 3-(6-malonylglucoside)-7,3"-di-(6-feruloylglucoside) (A2), cyanidin 3-(6"-caffeyl-2"-sinapylsambubioside)-5-(6-malonylglucoside) (A3), and two isomers of cyanidin 3-(2G-glucosylrutinoside)
(A4 and A5) (Table 1). The majority of Arabidopsis flavonoids were found to be anthocyanins, glycosylated kaempferol and rhamnosylated in this study which concurs with previously published findings [30-33].

Significant changes in the biosynthesis of flavonoids occurred that depended on treatment and time of application, except for F8 (Figures 1 and 2). One time application of products (TI) induced the peak area of F1, F2, F3, F4, F5, F6, F7, F8, and F9, compared to control (Figure 1). Similarly, but to a lesser extent, peak area levels of F1, F2, F3, F4, F5, F7, F8 and F9 were increased in the TII treatments compared to control (Figure 1). When compared between TI and TII treatments, TI treatments increased the peak area of F1, F2, F3, F4, F5, F6, F7, F8, and F9 compared to TII. The compound kaempferol, F6, which was detected at Rt11.43 (F6; $m / z$, 286.04) in the hydrolyzed leafy extracts, was induced significantly in the TI treatments compared to control and TII. The peak area of apigenin (a flavones containing compound, F8), did not change with the treatments, but F9 increased significantly in both TI and TII treated plants, while no significant difference was found in the peak area level of F9 between the treatments. The five anthocyanin derivatives (A1-A5) were increased in both TI and TII treated plants compared to control (Figure 2). TI induced the level of A2 and A4 significantly compared to TII and control (Figure 2). Comparing TI and
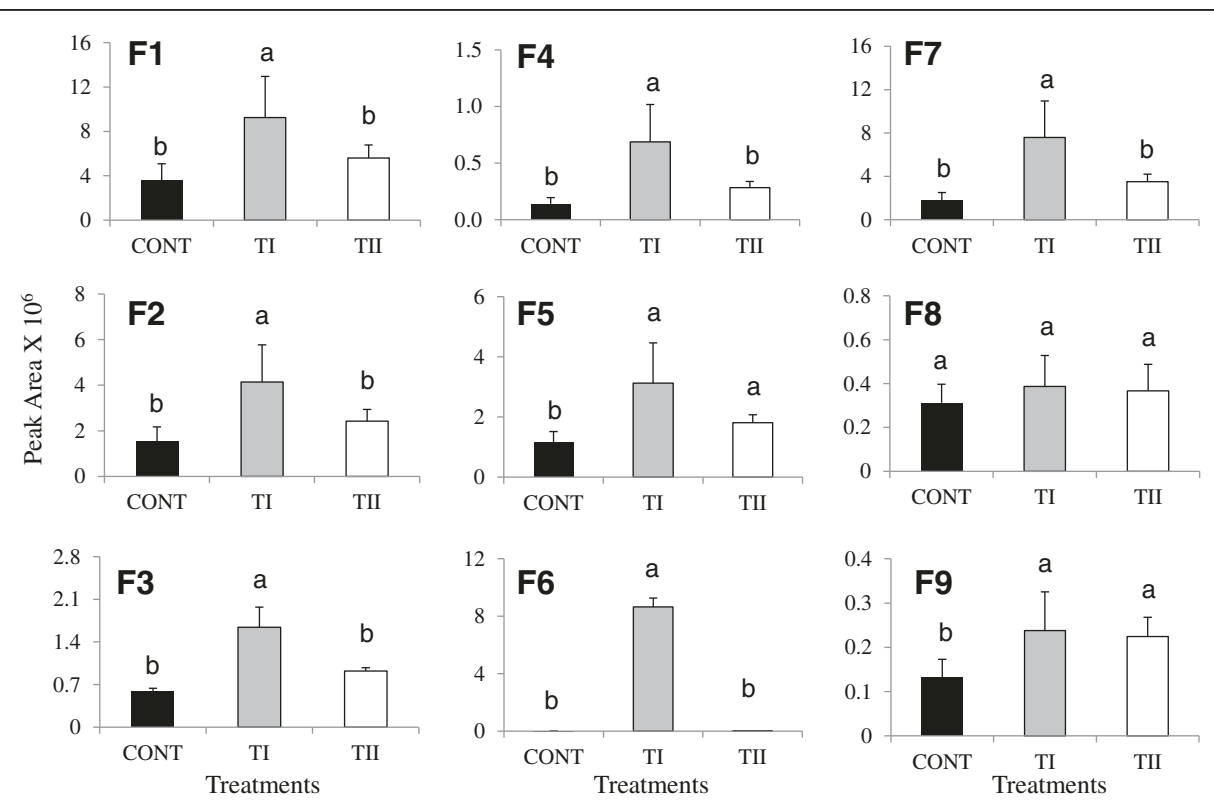

Figure 1 Profiles of flavonol glycoside detected in Arabidopsis thaliana treated once (TI) and multiple times (TII) with SoilBuilder ${ }^{\mathrm{TM}}$-AF (SB). Kaempferol-3,7-O-bis-alpha-L-rhamnoside (F1), kaempferol-3-O-alpha-L-rhamnopyranosyl (1-2)-beta-D-glucopyranoside-7-O-alpha-L-rhamnopyranoside (F2), Kaempferol with rhamnoside (F3), Kaempferol with rhamnoside (F4), Kaempferol with rhamnoside (F5), Kaempferol in hydrolyzed (F6), quercetin 3,7-dirhamnoside (F7), apigenin 7-(2",3"-diacetylglucoside) (F8) and pentamethoxydihydroxyflavone (F9). Bars indicate standard error of three biological replicates at each sampling time-point. Different letters in different bar differ significantly from the control according to Fit Least Squares (FLS) test, $P \leq 0.05$. CONT (black bar) indicates the untreated plants, TI (shaded) and TII (white) treated with microbial products only once and multiple times, respectively. 


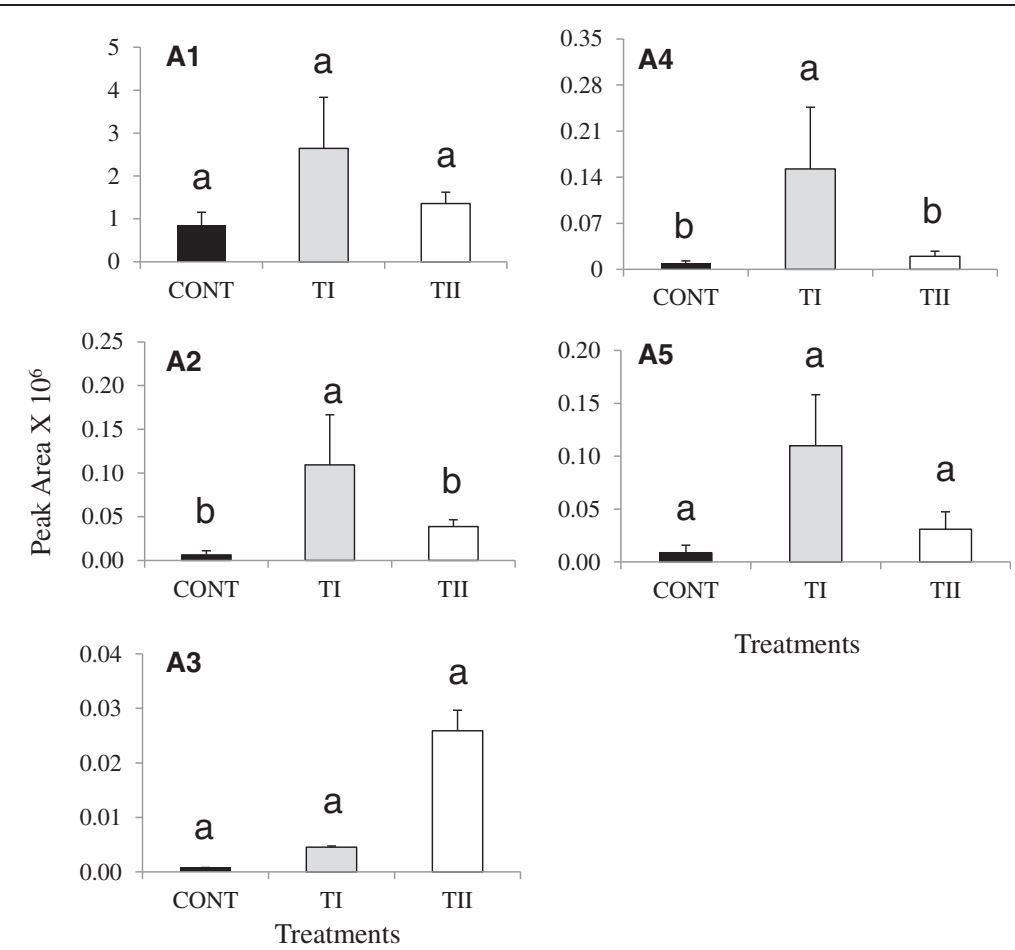

Figure 2 Profiles of anthocyanidins glycoside detected in Arabidopsis thaliana treated once (TI) and multiple times (TII) with SB. Cyanidin -Rhamnoglucoside (A1), cyanidin 3-(6-malonylglucoside)-7,3'-di-(6-feruloylglucoside) (A2), cyanidin 3-(6"-caffeyl-2"-sinapylsambubioside)-5(6-malonylglucoside) (A3) and cyanidin 3-(2G-glucosylrutinoside) (A4) and cyanidin 3-(2G-glucosylrutinoside) (A5). Bars indicate standard error of three biological replicates at each sampling time-point. For significant level identification, see Figure 1.

Table 1 Flavonoids identified in Arabidopsis thaliana leaf tissue by liquid chromatography-electrospray ionization Q- time of flight - mass spectrometry (LC/ESI- Q-TOF MS/MS) analysis

\begin{tabular}{|c|c|c|c|c|}
\hline Peak no. & Rt (min) & $\begin{array}{c}\text { ESI-MS } \\
(m / z)\end{array}$ & Mol formula & Compound name \\
\hline 1 (A4) & 7.1294 & 757.2185 & $\mathrm{C}_{33} \mathrm{H}_{41} \mathrm{O}_{20}$ & Anthocyanidin 3-(2G-glucosylrutinoside) \\
\hline $2(\mathrm{~F} 2)$ & 7.3303 & 740.2166 & $\mathrm{C}_{33} \mathrm{H}_{40} \mathrm{O}_{19}$ & $\begin{array}{l}\text { Kaempferol-3-O-alpha-L-rhamnopyranosyl (1-2)-beta-D-glucopyranoside-7-O-alpha-L- } \\
\text { rhamnopyranoside }\end{array}$ \\
\hline $3(\mathrm{~F} 3)$ & 7.3482 & 432.1062 & $\mathrm{C}_{21} \mathrm{H}_{20} \mathrm{O}_{10}$ & Kaempferol with rhamnosides \\
\hline $4(\mathrm{~A} 1)$ & 7.4932 & 595.1674 & $\mathrm{C}_{27} \mathrm{H}_{31} \mathrm{O}_{15}$ & Anthocyanidin 3-Rhamnoglucoside \\
\hline $5(\mathrm{~A} 5)$ & 7.5893 & 757.2188 & & Anthocyanidin 3-(2G-glucosylrutinoside) \\
\hline $6(\mathrm{~F} 5)$ & 7.7591 & 432.1062 & $\mathrm{C}_{21} \mathrm{H}_{20} \mathrm{O}_{10}$ & Kaempferol with rhamnosides \\
\hline $7(F 7)$ & 7.7687 & 594.1596 & $\mathrm{C}_{27} \mathrm{H}_{30} \mathrm{O}_{15}$ & Quercetin 3,7-dirhamnoside \\
\hline $8(\mathrm{~A} 2)$ & 7.7707 & 1211.305 & $\mathrm{C}_{56} \mathrm{H}_{59} \mathrm{O}_{30}$ & Anthocyanidin 3-(6-malonylglucoside)-7,3'-di-(6-feruloylglucoside) \\
\hline $9(\mathrm{~A} 3)$ & 7.9512 & 1197.293 & $\mathrm{C}_{55} \mathrm{H}_{57} \mathrm{O}_{30}$ & Anthocyanidin 3-(6"-caffeyl-2"-sinapylsambubioside)-5-(6-malonylglucoside) \\
\hline $10(\mathrm{~F} 9)$ & 8.1942 & 362.0622 & $\mathrm{C}_{17} \mathrm{H}_{14} \mathrm{O}_{9}$ & Pentamethoxydihroxyflavone \\
\hline $11(\mathrm{~F} 8)$ & 8.2139 & 516.1278 & $\mathrm{C}_{25} \mathrm{H}_{24} \mathrm{O}_{12}$ & Apigenin 7-(2",3"-diacetylglucoside) \\
\hline $12(\mathrm{~F} 1)$ & 8.2625 & 578.1646 & $\mathrm{C}_{27} \mathrm{H}_{30} \mathrm{O}_{14}$ & Kaempferol-3,7-O-bis-alpha-L-rhamnoside \\
\hline $13(\mathrm{~F} 4)$ & 8.2657 & 432.1067 & $\mathrm{C}_{21} \mathrm{H}_{20} \mathrm{O}_{10}$ & Kaempferol with rhamnosides \\
\hline $14(\mathrm{~F} 6)$ & 11.434 & 286.048 & $\mathrm{C}_{15} \mathrm{H}_{10} \mathrm{O}_{6}$ & Kaempferol \\
\hline
\end{tabular}

$R t$, retention time; ESI-MS, electrospray ionization/mass spectrometry; $\mathrm{m} / \mathrm{z}$, mass/charge. 
TII treatments, the TI treatment increased the level of A1, A2, A4, and A5) compared to TII. Nevertheless, TII treatment increased the level of A3 compared to TI.

\section{Expression of flavonoid biosynthesis genes in Arabidopsis leaves}

To understand the influence of microbial product application timing (TI and TII) on the flavonoid pathway, the expression of genes encoding key PP pathway enzymes PAL1, PAL2, PAL3, PAL4, C4H, CHS, CHI, F3H, F3'H, FLS1, DFR, $L D O X$, and UF3GT were analyzed in Arabidopsis leaves using qPCR (Figures 3 and 4). Both types of treatments (TI and TII) did not induce the expression PAL1, PAL2, PAL3 and $P A L 4$ significantly $(P \geq 0.05)$ compared to control (Figure 3). Expression of CHS, FLS1, LDOX, and UF3GT was induced double in both types of treatments compared to the control, while TI and TII treatments increased expression of $F 3$ 'H 8 and 4 times more compared to control, respectively (Figure 4). Expression of $\mathrm{CHI}$ increased significantly $(P \leq 0.05)$ in TI compared to control and TII treated plants, while CHI expression did not change significantly in TII treated plants compared to the control. Expression of $F 3 H$ increased significantly ( $P \leq$ $0.05)$ in TII compared to control and TI treated plants, while $F 3 H$ expression did not change significantly in TI treated plants compared to the control. TI treatment increased expression of $D F R$ by one fold compared control and no change of DFR expression was found in TII treated plants compared to control. Acylation genes
(At1g03495, At1g03940 and At3g29590), glycosylation genes (UGT75C1 and UGT78D3), GST and UDP-rhamnose synthase genes (RHM1, RHM2, and RHM3) increased in the TI and TII treated plants compared to control in the majority of the cases (see Additional files 2A, B and C).

\section{Expression pattern of flavonoid pathway regulatory genes in Arabidopsis leaves}

To examine whether the induced expression of flavonoid biosynthetic genes in leaves was accompanied by the expression of regulatory genes, we analyzed the transcript levels of PAP1, PAP2, MYB11, MYB12, MYB111, MYB113, MYB114, GL3, EGL3, TT8 and TTG1 in the leaves of Arabidopsis treated with TI and TII (Figure 5). Expression of most of the regulatory genes was induced in both TI and TII treated plants compared to control. Expression levels of $P A P 1$ and $P A P 2$ were increased in both TI and TII treated plants compared to the control; and even more so for PAP2 in the TI treated plants, which experienced a 3-fold increase. Expression of $M Y B 11, M Y B 12$, $M Y B 113$ and MYB114 were increased in both TI and TII treated plants compared to control. Expression of $M Y B 12$ and $M Y B 114$ was induced to the greatest extent in the TI compared to TII treated plants. Expression of MYB11 and MYB113 was induced in both TI and TII treated plants compared to control. Conversely, MYB111 expression in the TII treatment was suppressed, and the TI treatment only slightly up-regulated. The effect of treatment on GL3 and TTG1 expression levels was similar with no induction
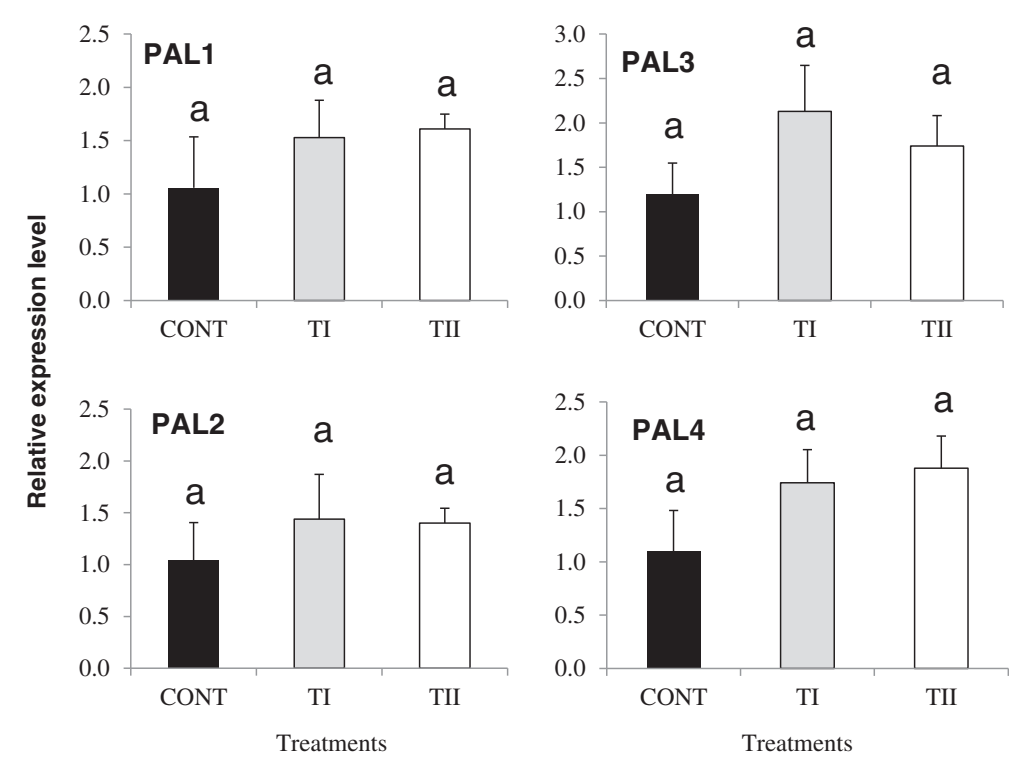

Figure 3 Relative transcript abundance of phenylalanine ammonia lyase (PAL) of flavonoid pathway (PAL1, PAL2, PAL3 and PAL4) genes known to be involved in flavonoid biosynthesis in Arabidopsis thaliana after being treated once (TI) and multiple times (TII) with SB. Primers used in these studies, products size for the amplified fragments, accession numbers are shown in Additional file 6. Transcript abundance of each gene was normalized by the level of an actin and EF-1a gene. Bars indicate standard error of three biological replicates at each sampling time-point. For significant level identification, see Figure 1. 

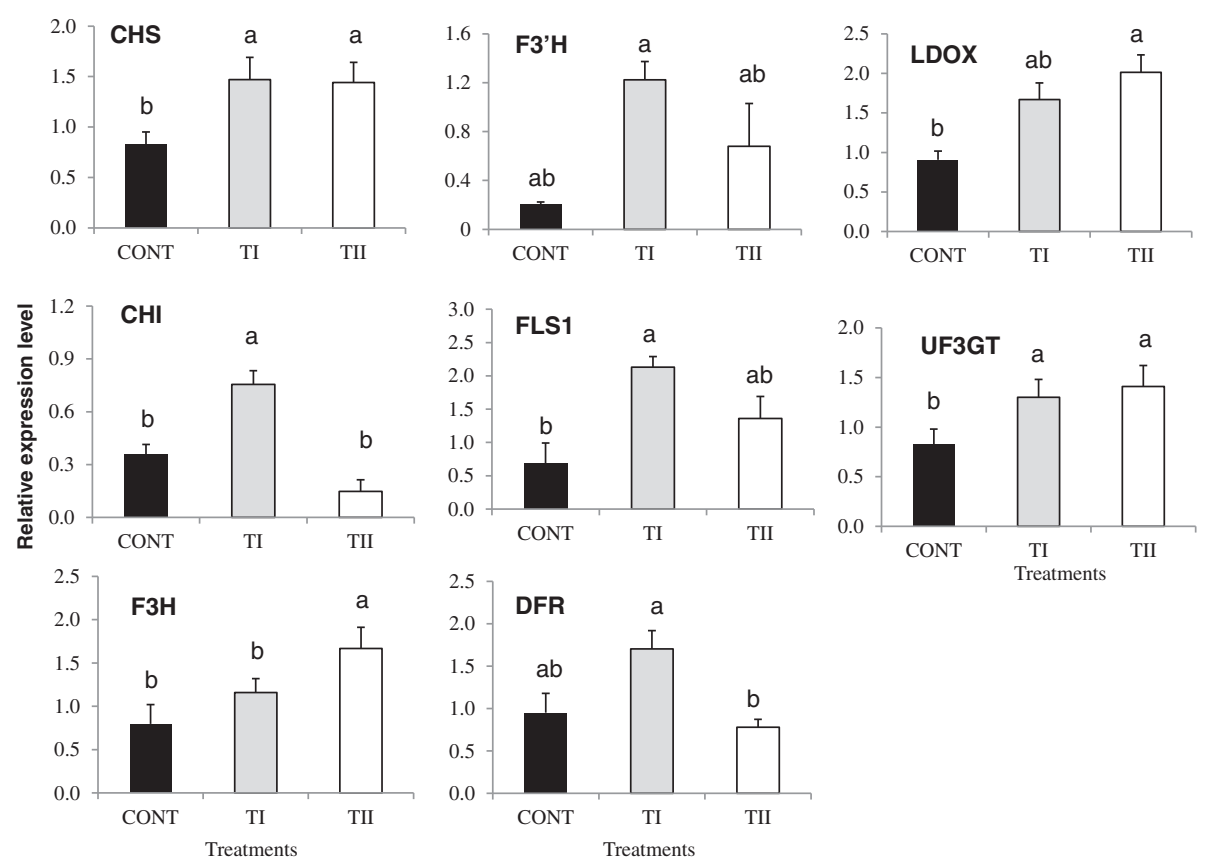

Figure 4 Relative transcript abundance of flavonoids pathway structural genes (CHS, CHI, F3H, F3' $H, F L S 1$, UF3GT, DFR and LDOX) known to be involved in flavonoid biosynthesis in Arabidopsis treated once (TI) and multiple times (TII) with SB. Primers used in these studies, products size for the amplified fragments, accession numbers are shown in Additional file 6. Transcript abundance of each gene was normalized by the level of an actin and EF-1a gene. Bars indicate standard error of three biological replicates at each sampling time-point. For significant level identification, see Figure 1.

for the TI and control, whereas expression of both genes increased significantly $(P \leq 0.05)$ compared to TI and control. Expression of EGL3 did not change in both TI and TII treated plants compared to control. Strong increase in the expression levels of TT8 was noted in the TI treated plants compared to control.

\section{Lignin biosynthesis}

To further understand the application of microbial treatments (TI and TII), we analyzed the expression of all the genes (20) involved in the lignifications pathway (Figures 3, 6, 7 and Additional file 3). The accumulation of transcripts for $C 4 H, 4 C L 1, C 3 ' H 1, C C o A O M T 1, C C R 1, C C R 2$, COMT1, CAD1, CAD3, CAD4, CAD5, CAD7, CAD8 and $S A T$ were induced significantly $(P \leq 0.05)$ in TI treated plants compared to control. Expression levels of $H C T$, $F 5 H 1$, and $S A T$ were increased significantly $(P \leq 0.05)$ in TII treated plants compared to control. No significant $(P \geq 0.05)$ difference of expression levels of C3'H1, CCR1, $C C R 2$, and COMT1 were observed between control and TII treated plants. We found that expression levels of $C C R 2, C A D 1, C A D 5, C A D 7$, and CAD8 were increased significantly $(P \leq 0.05)$ in TI compared to TII treated plants. Expression of $L A C 4, L A C 17$, and their regulatory genes (SND1, MYB58, and MYB63) increased significantly $(P \leq 0.05)$ in both TI and TII treated plants compared to control (Additional file 4$)$, and also with significant $(P \leq$
0.05) expression levels for the TI compared to the TII treated plants. Significant $(P \leq 0.05)$ accumulation of lignin was noted in the TI and TII treated plants compared to control.

\section{Discussion}

\section{Expression of flavonoid pathway genes and} metabolite composition

Our study provides evidence that application of microbial products (TI and TII) to Arabidopsis plants increases the accumulation of flavonoids, and that TI resulted in greater accumulation of metabolites than TII treated plants. Such enhancement was accompanied by an increased expression of most of the genes in the flavonoid biosynthetic pathway. This was particularly prominent in TI treated plants, but there were also elevated expression levels in TII treated plants. Synthesis of the derivatives of kaempferol, quercetin, and anthocyanins depend greatly on dihydrokaempferol. Meanwhile, F3'H and FLS1 are crucial to channeling the precursor's dihydroquercetin/dihydrokaempferol, forming quercetin or kaempferol branches. The up-regulation of F3' $H$ and FLS1 in TI compared with TII treated plants are consistent with an increase in the amounts of most of flavonol glycosides in Arabidopsis leaves (Figure 1). However, in TII treated plants, there was a significant decrease in the amounts of most of flavonol glycosides compared to TI, which is also in accordance 


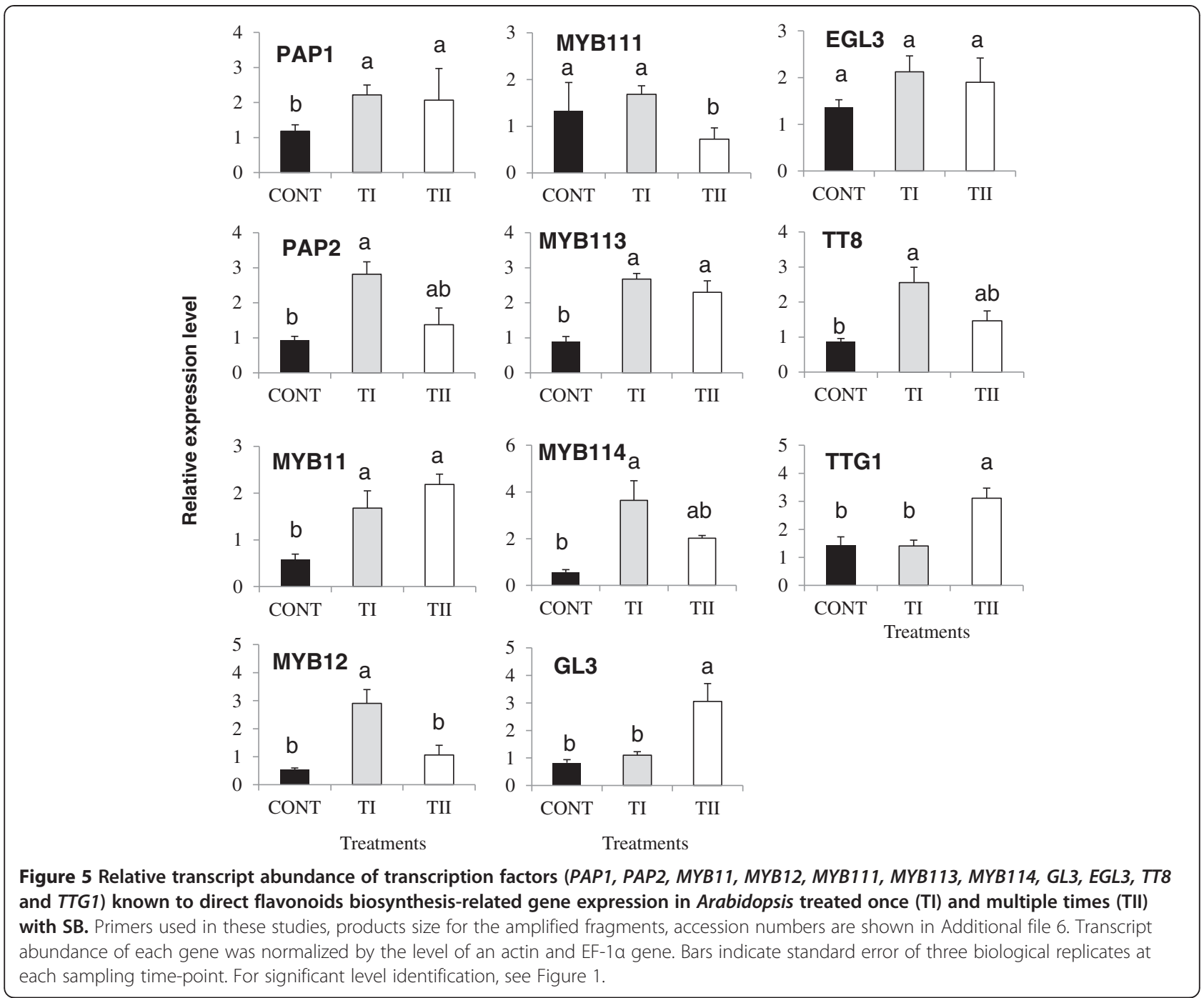

with the down-regulation of $F 3^{\prime} H$ and $F L S 1$ observed in TII treated plants. Such difference may be due to the variability of specific substrate, which can make the biosynthetic pathway different, thus producing different products. Therefore, the increase of kaempferol-containing flavonols is primarily associated with the accumulation of F1, which is 2-fold higher as compared to F2, F3, F4, F5, F7, and F9 in TI treated plants.

LC-MSMS analyses detected a strongly increased level of a compound (F6) in acid hydrolyzed samples corresponding to molecular mass $(\mathrm{m} / \mathrm{z}, 286.0)$ of aglycone kaempferol. Consistent with the induced expression of DFR, LDOX and UF3GT in both TI and TII treated plants, we observed significant increases in the amount of anthocyanins (A1, A2, A3, A4 and A5) in the leaves of Arabidopsis as compared to the control (Figure 2). The effect was most prominent for A1, A2, A4 and A5 in the TI treated plants wherewith higher accumulation was observed compared to those plants receiving the TII treatment. In contrast, plants treated with TII showed higher accumulation of A3 compared to control. The presence of caffeyl, ferulyl, sinapyl and malonyl groups in the accumulated anthocyanins is parallel with the induced expression of anthocyanin acyltransferases, and SAT in the present study [34]. The accumulation of these compounds could provide some level of increased defense against biotic and abiotic stresses. For example, the presence of the acylated flavonol glycosides in the leaf hairs of Quercus ilex increased the plant's protection against the damage of UV-B radiation [35]. In another example, rutin showed significant antifungal activity against the fungi Cylindrocar pondestructans, Phytophthora megasperma, and Verticillium dahlia attacking olive trees (Olea europaea). Rutin is, therefore, believed to play a major role in plant defense [36]. The formation of a large number of glycoslated kaepmferol derivatives and only a small amount of glycosylated anthocyanidins in our study are corroborated by earlier reports $[37,38]$. 

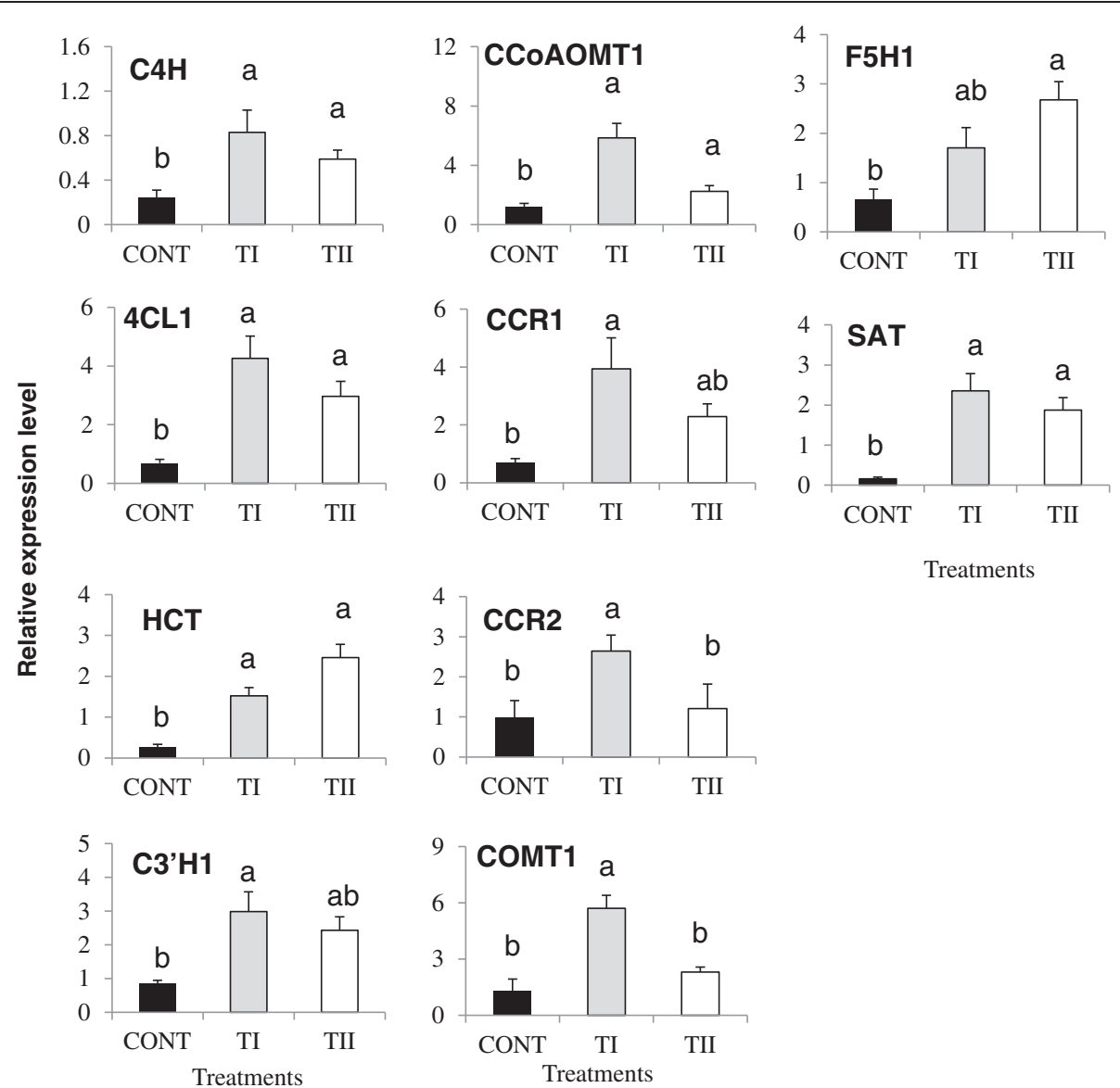

Figure 6 Relative transcript abundance of structural genes (C4H, 4CL1, HCT, C3'H1, CCOAOMT1, CCR1, CCR2, COMT1, F5H1, and SAT) known to involved in lignin biosynthesis in Arabidopsis treated once (TI) and multiple times (TII) with SB. Primers used in these studies, products size for the amplified fragments, accession numbers are shown in Additional file 6. Transcript abundance of each gene was normalized by the level of an actin and EF-1a gene. Bars indicate standard error of three biological replicates at each sampling time-point. For significant level identification, see Figure 1.

Several GTs that are involved in the glycosylation processes and induced expression of UGT75C1 and UGT78D3 $[30,38]$ are consistent with the expression of FLS1, F3'H, and glycosylated flavonol compound biosynthesis in TI and TII treated plants. Rhamnosylation is a major glycosylation process of flavonols and the genes responsible for biosynthesis of rhmanose sugar, and is vital in supplying $U D P$-rhamnose for flavonol biosynthesis. Enhanced expression of RHM1, RHM2 and RHM3 in the TI and TII treated plants suggests their possible roles in the formation of Rha residue and rhamnosylation of flavonoids. Our LCMSMS data also suggest that most flavonol accumulation in the microbial treated plants is in the rhamnosylated form. Induced expression of rhamnosylated genes was reported in Arabidopsis [31], confirming previous results that suggest its involvement in rhamnosylation of flavonols in TI and TII treated plants. The induced expression of RHM1, RHM2, and RHM3 in our study may be due to either competition of substrate availability, or to changes in the flow of flux in the different branches of the PP pathway, a phenomenon which has been reported in Arabidopsis $[39,40]$. These results showed significant variation in flavonoid accumulation, indicating that the accumulation of flavonoid may potentially be manipulated by altering the application timing of the microbial based products.

\section{Transcriptional regulation of flavonoid pathway genes}

Transcriptional regulation of flavonoid biosynthesis structural genes are controlled by regulatory genes, which provide an additional level of control. Several $M Y B / b H L H /$ $W D$-repeat $(M B W)$ family genes have been implicated in the regulation of flavonoid biosynthesis in Arabidopsis. Among them, PAP1 is a master regulator of flavonoid/ anthocyanin biosynthesis pathway [41]. Our results suggest that induced expression of PAP1 and its close homo$\log , P A P 2$, are strongly induced in TI and TII treated plants, regulating the flavonoid biosynthesis. Interestingly, 


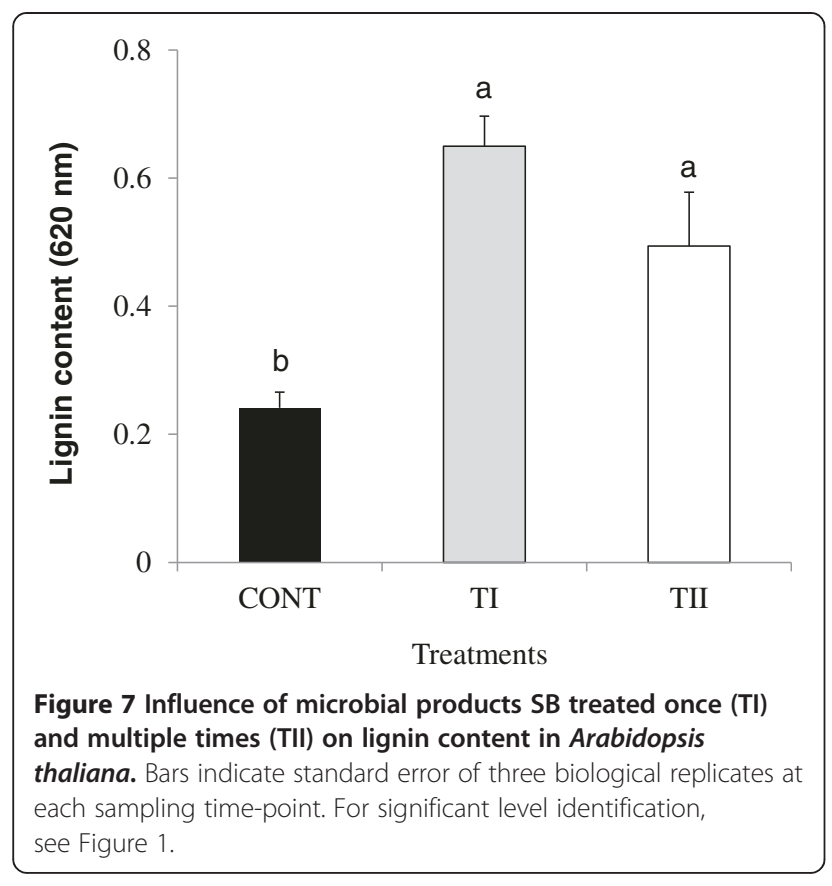

PAP2 expression was increased in TI treated plants as compared to PAP1. Thus, it is reasonable to suggest that $P A P 2$ expression was stable enough to control flavonoid biosynthesis.

There are several other genes encoding $M Y B$ and $b H L H$ transcription factors (TF) that are known to be involved in regulating flavonoid biosynthesis in Arabidopsis leaves. Therefore, the expression of MYB11, MYB12, MYB111, MYB113, MYB114, GL3, EGL3, TT8 and TTG1 was analyzed. TT8 interacts with PAP1/PAP2 [42], and the upregulation of $P A P 1 / P A P 2$ and TT8 genes appears to be required for the activation of anthocyanin structural genes for anthocyanin production in TI treated plants. The closely related MYB11, MYB12, and MYB111 TFs are flavonolspecific regulators, and effect flavonol accumulation in different parts of the Arabidopsis seedlings by regulating several genes of flavonoid biosynthesis, such as $\mathrm{CHS}, \mathrm{CHI}$, $F 3$ 'H, and FLS1 [21]. Consistent with the up-regulation of $P A P 1$ and $P A P 2$, induced expression of MYB11, MYB12, $M Y B 113$ and $M Y B 114$ genes resulted in an increase in the content of individual flavonol biosynthesis in the TI compared TII treated plants. However, induced expression of $P A P 1, M Y B 11$ and $M Y B 113$ gene coincided with reduced expression of PAP2, MYB12, MYB111 and MYB114 in the TII treated plants, suggesting a balance among $M Y B$ gene members in controlling the flavonoid biosynthesis in our study. Variable regulation of the TFs and regulatory genes in the TII treated plants likely led to the lower amounts of flavonols and anothcyanin and higher amounts of F8, F9 and A3 observed in these plants.

Interestingly, a significant increase in the amounts of A3 was noted in the TII as compared to TI treated plants that may have been due to the induced expression of regulatory genes GL3 and TTG1, and anthocyanin biosynthetic genes $L D O X$ and UF3GT. Previous studies have indicated that the mutant of $\operatorname{tg} 1$ disrupted the expression of late anthocyanin biosynthetic genes such as DFR and $L D O X$, whereas the expression of 'early' anthocyanin biosynthetic genes (CHS, $\mathrm{CHI}$, and $\mathrm{F} 3 \mathrm{H}$ ) is not effected in the same mutant $[22,43,44]$. Our results show that genes involved in the biosynthesis of flavonoids are expressed differently in TI and TII treated plants, which explains why some of the flavonoids are produced in much higher amounts as compared to the control. This clearly indicates some correlation between the biosynthesis of these closely related flavonoids in response to plants receiving the microbe-based soil additive. However, further work is required to understand whether these changes are due to the microbes or metabolites in the product, or the interaction of the two, and if they are acting directly on the plant or indirectly by mediating the interaction of the plant with the surrounding soil.

\section{Expression of transcription factors during lignin accumulation}

A branch of the PP pathway is responsible for the synthesis of lignins by the coordinated transcription of lignin pathway genes (C4H, 4CL1, C3'H1, CCoAOMT1, CCR1, CCR2, COMT1, CAD1, CAD3, CAD5, CAD7, CAD8 and SAT) [45-49]. TI strongly induced the expression of $C 4 H, 4 C L 1$, HCT, C3'H1, CCOAOMT1, CCR1, CCR2, COMT1, CAD1, $C A D 3, C A D 5, C A D 7, C A D 8$ and $S A T$, whereas TII induction of lignin biosynthesis genes is relatively low, with the exception of HCT and F5H1, whose expression levels were higher in the TII compared to TI treated plants (Figure 6 and Additional file 3). C4H, 4CL1, and HCT have been shown to be involved in lignification [50-52]; furthermore, the increase in the expression levels of $C 4 H, 4 C L 1$, and $H C T$ in the TI and TII treated plant could be linked to the lignification process. CCOAOMT1 and COMT1 expression was induced in TI and TII treated plants. CCoAOMT1 encodes an enzyme involved in monolignol biosynthesis by catalyzing the methylation of caffeyl-CoA ester. Moreover, in TI treated plants, the up-regulation CCoAOMT1 and COMT1 were observed more than those of TII treated plants. Overexpression of PAP1 (a positive regulator of anthocyanin biosynthesis) in Arabidopsis showed increased amounts of guaiacyl and syringyl monomers that were associated with increased lignin accumulation [24]. In Vitis vinifera, $V v M Y B 5 a$, which regulates anthocyanin and proanthocyanidin biosynthesis in grapevine, also affects lignin biosynthesis. Overexpression of $V v M Y B 5 a$ in tobacco down regulated $C C O A O M T 1$ gene expression, leading to reduced lignification in anther walls and delayed dehiscence [53]. It was also observed that $C 4 H$ and $C O M T 1$ genes are regulated by a lignin-specific $M Y B$ transcription factor MYB58 in Arabidopsis [54,55]. 
Of the two $C C R$ isogenes, CCR1 showed higher overall expression levels than CCR2 in both TI and TII treated plants, but only plants form TI had greater CCR1 expression compared to control. Up-regulation of $C C R$ expression has been associated with an increase in lignin formation in Arabidopsis [56]. Nine CAD genes have been reported in Arabidopsis [48]. The results showed that six members of the $C A D$ family genes (CAD1, CAD3, CAD4, CAD5, CAD7, and CAD8) accumulated at varying levels, with $C A D 1, C A D 3, C A D 7$ and $C A D 8$ expression being higher in the TI treated plants compared to TII treated plants (Additional file 3). $C A D 4$ and $C A D 5$ have been shown to play a major role in lignifications [57]. We observed that CAD4 and $C A D 5$ expression was induced to the same degree in both TI and TII treated plants compared to control. A role of $C A D 1$ in lignification has been shown in young stems, flowers, and siliques of Arabidopsis [58]. CAD3 expression was detected in secondary growth in hypocotyls of $A$. thaliana [59]. A several fold increase in the levels of expression of $C A D 7$ and $C A D 8$ was noted in the TI treated plants compared to TII treated plants; however, their expression was increased in the TII treated plants compared to control plants. The higher induced expression levels of $C A D 7$ compared to $C A D 8$ was also observed in plantlets and flowers of Arabidopsis [58]. Thus, different members of the $C C R$ and $C A D$ family genes appear to be induced differently in lignin biosynthesis in plants treated with microbe-derived products. The induced expression of these genes in our study suggested that they might contribute to the biosynthesis of lignin. At $2 g 23000$, encoding sinapoylglucose:anthocyanin sinapoyltransferase $(S A T)$, plays a role in sinapoylmalate synthesis [60] an increase in the expression levels of $S A T$ in the TI and TII treated plant was also noted.

Both $C C R$ and $C A D$ are critical for lignin biosynthesis, transferred into the cell wall, and polymerized by laccases $[61,62]$. The up-regulation of laccases ( $L A C 4$ and $L A C 17$ ) is accompanied by the up-regulation of several TFs in both TI and TII treated plants responsible for controlling lignin biosynthesis (Additional file 4). It was shown that $L A C 4$ is expressed in vascular bundles and interfascicular fibers; and, that $L A C 17$ contributes in the interfascicular fibers lignifications [63]. Secondary wall associated NAC domain protein1 (SND1), a key transcriptional activator regulating the developmental program of secondary wall biosynthesis [64], was induced in TI and TII treated plants compared to control (Additional file 4). MYB58 and $M Y B 63$ have been suggested to be specific activators for lignin biosynthesis [55]. The induced expression of these genes in both TI and TII treated plants (Additional file 4) suggested that they are actively involved in the lignifications process.

\section{Conclusions}

This study shows that microbial products applied to the soil of growing plants support our hypothesis and results in induction of the PP pathway and increased metabolite biosynthesis. The one time application of microbial products (TI) produced more metabolites than multiple applications (TII). The higher metabolite biosynthesis in TI compared to TII could be explained by the fact that both TI and TII contained microbial products, while TII applied few times more compared to TI may have indirectly inhibit the metabolite biosynthesis or diverted the metabolites to other metabolic pathway. However, overall flavonoid accumulation was higher in the treated plants, regardless of timing, as compared to the control. Such differences in the flavonols and anthocyanin accumulations between TI and TII treated plants can be explained by the differential transcript accumulation of structural and regulatory genes in leaves of Arabidopsis. This is one of the first studies to show that microbial products play an important role in activating the PP pathway in leaves of Arabidopsis. These results suggest that the mechanism(s) responsible for the enhancement of metabolites could be related to the microorganisms or metabolites in the product, or an interaction of both. Innovative approaches are needed such as pyro-sequencing for the identification of specific microbial groups, and metabolomics analysis for the identification of possible bioactive metabolites within the product to evaluate those responsible for activation of the transcriptional cascade observed in this study.

\section{Methods}

\section{Source of microbial preparation}

Soil Builder ${ }^{\mathrm{Tm}}$-AF, SB (Advanced Microbial Solutions, Pilot point, TX, USA), a biochemical fertilizer catalyst developed specifically for the agriculture industry, contains bacteria products derived from a bioreactor system consisting of a large and diverse microbial community. The microbial community composition of SB has been assessed using 16S rRNA based gene analysis and is generally composed of species of bacillus, actimomyces and proteobacteria. Previous works also reported that SB consists of bacillus species, actinomycetes, cyanobacteria, algae, protozoa, and microbial by-products [65] including microbial metabolites produced during anaerobic fermentation of a microbial community [66]. Basic chemical composition of the product was determined by the University of Kentucky Soil Testing Laboratory following standard protocols (Additional file 5).

\section{Growth conditions and treatment procedure}

Seeds of Arabidopsis thaliana ecotype Columbia-0 were sterilized and sown on solid $0.7 \%$ agar plates containing $1 \times$ Murashige and Skoog medium ( $\mathrm{pH}$ 5.7). Plates were incubated in darkness at $4^{\circ} \mathrm{C}$ for 2-3 days and were 
transferred to a growth chamber at $22^{\circ} \mathrm{C}$ with a $16-\mathrm{h}$ light/8-h dark cycle at a photosynthetic photon flux density (PPFD) of $100 \mu \mathrm{mol} \mathrm{m} \mathrm{m}^{-2} \mathrm{~s}^{-1}$, and $65-70 \%$ relative humidity and grown for two weeks. After two weeks seventy of the seedlings were transferred to six inch pots containing fertilizer (PRO-MIX. BX, Quakertown, PA, USA), arranged in randomized complete block design in the growth chamber and allowed to acclimate for 710 days. Plants were treated following the manufacturers recommended application rate of $100 \mathrm{ml}$ of $6 \times$ concentrated $16 \mathrm{ml} / \mathrm{L} \mathrm{SB}$. For TI, individual plants were treated with the products only on $1^{\text {st }}$ day, and in parallel with same solutions for $1^{\text {st }}$ day and every $3^{\text {rd }}$ day for TII. Control plants were treated with same water in every $3^{\text {rd }}$ day. Each set of treatment have 18-20 plants including control. On day 14, from each set 5-6 plants were divided randomly to collect representative of biological replicates (R1, R2 and R3). Leaves were collected on day 14 (control and treated), weighed, and were immediately frozen in liquid nitrogen and stored at $-80^{\circ} \mathrm{C}$ until RNA extraction.

\section{RNA extraction, CDNA synthesis and Quantitative real- time PCR (qPCR)}

Total RNA was extracted from three biological replicates using TRI-ZOL method following the manufacturer instructions. cDNA synthesis and qPCR analysis was done according to the method of [67]. Transcript levels in Arabidopsis were measured in triplicates of each biological replicate by qPCR, using SYBR Green (Applied Biosystem) in the Applied Biosystem StepOnePlus ${ }^{\text {TM }}$ Real-Time PCR Systems following the manufacturer's manual. The relative mRNA levels were determined by normalizing the PCR threshold cycle number of each gene with that of the $E F$ $1 \alpha$ and ACTIN as reference genes, according to GeneEx software (http://www.multid.se/order/bioeps.php;) and the data were the average of three replicates. Sequences of primers used in this study were retrieved from literature and used for amplifying gene-specific sequences (Additional file 6 [24,25,27,31,48,68-77].

\section{Identification and quantification of flavonoids and anthocyanins by LC-ESI-QTOF-MS/MS method}

Metabolite profiling was performed as described by Lea et al. (2007) with some modifications. Approximately $100 \mathrm{mg}$ frozen leaves from three biological were homogenized under liquid nitrogen and transferred to a $2 \mathrm{~mL}$ Eppendorf tube, to which was added $1 \mathrm{~mL}$ of methanol. The phenolics were extracted for $18 \mathrm{~h}$ at room temperature in darkness, and centrifuged at 14,000 rpm for $15 \mathrm{~min}$. The extract was filtered through a sterile Syr filter $(25 \mathrm{~mm}$, $0.20 \mu \mathrm{m})$ through sterile syringe (MicroLiter Analytical Supplies, Inc). Acid hydrolysis was performed by adding $30-\mu \mathrm{l}$ of $3 \mathrm{~N} \mathrm{HCL}$ into the sample, and then heated for an hr at $70^{\circ} \mathrm{C}$ in water bath. The accuracy of machine was tested in the extract of samples before running analyses, and we injected a mix of flavonoids to make sure flavonoids were working in LC-MSMS method that included the following: Apigenin-7-glucoside, liquiritigenin, geninstein, quercetin, apigenin, and epicatechin. Profiling of metabolites (flavonoids and anthocyanins) in leaf extracts was performed using an LC system with pump model 1200 with 6530A (Agilent Technologies, CA, USA) quadrupole time of flight (Q-TOF) mass spectrometer equipped with an Agilent Jet Stream electrospray ionization (ESI) ion source. The ESI source used a separate nebulizer for the continuous introduction of reference mass compounds: 121.050873, 922.009798 (positive ion mode). Five microliters of sample extract was separated using an Acquity BEH Shield RP-18 analytical column $(1.7 \mu \mathrm{m} 2.1 \times 150 \mathrm{~mm}$, Waters Corporation, Milford, CT) maintained at $40^{\circ} \mathrm{C}$. The mobile phase of solvent A consists of water/formic acid (99.9:0.1, v/v) and (B) acetonitrile/formic acid (99.9:0.1, $\mathrm{v} / \mathrm{v}$ ) with a solvent ratio of $\mathrm{A}: \mathrm{B}$ of $95: 5$. The following gradient for binary pump 1 was used with a total analysis time of $21 \mathrm{~min}$ and a flow rate of $0.25 \mathrm{~mL} / \mathrm{min}$ : $5 \%$ to $25 \%$ mobile phase B over 2 min then to $25 \%$ to $65 \%$ mobile phase B for 2.0 to $10.5 \mathrm{~min}$, then to $99 \%$ mobile phase B for 10.5 to $12.5 \mathrm{~min}$, then held at $99 \%$ mobile phase for 12.5 to $14 \mathrm{~min}$ followed by to $5 \%$ B from 14 to $15.5 \mathrm{~min}$ and then held at $5 \% 15.5$ to $17 \mathrm{~min}$.

The analytical conditions of mass spectrometry are as follows: range, start (100 amu), stop (1,700 amu), and scan time $(4.0 \mathrm{~s})$; heating gas temperature, $350^{\circ} \mathrm{C}$; gas flow (l/min), 8.0; nebulizing gas, 35 psi; Sheath gas temp, 350; Sheath gas flow 11.0; VCap 3000; nozzle voltage (V) 1000. The fragmentor voltage was $120 \mathrm{~V}$ and skimmer1 65 VandoctopoleRFPeak 750 and collision energies $(20 \mathrm{eV})$ were optimized for each compound. To confirm the identity of the flavonoids, MS/MS $(\mathrm{m} / z)$ fragmentation patterns were compared with those of previously published reports [41] and confirmed by accurate mass Q-TOF analyses. In the absence of authentic standards, the flavonoids were quantified by peak area. MSMS spectra were compared with LC ESI-Q-TOF- MS/MS spectra of known compounds from the ReSpect data base containing all flavonoids MS/MS spectra (published by Prof Kazuki Saito, JP) and Metlin (the Agilent MS/MS spectral library). Results are reported as the mean of the three replicates.

\section{Lignin measurement}

Lignin was measured quantitatively according to [78]. Leaves were homogenized in liquid $\mathrm{N}_{2}$. The powdered was transferred to a tube and suspended in $1.5 \mathrm{ml}$ of methanol, and vigorously stirred for $1 \mathrm{~h}$. The homogenate was centrifuged for $15 \mathrm{~min}$ at $14,000 \mathrm{rpm}$, the pellet was 
washed with $1.5 \mathrm{ml}$ of the following solvents by vortexing for $15 \mathrm{~min}$ : (i) methanol twice; (ii) $1 \mathrm{M} \mathrm{NaCl}$; (iii) $1 \% \mathrm{SDS}$; (iv) water twice; (v) $\mathrm{CHCl}_{3} / \mathrm{CH}_{3} \mathrm{OH}$ (1:1); and (vi) tertbutyl methyl ether. The final pellet was freeze-dried overnight, and $10 \mathrm{mg}$ was taken for the following assay. The powder was treated with $1 \mathrm{ml}$ of $2 \mathrm{M} \mathrm{HCl}$ and $0.2 \mathrm{ml}$ of thioglycolic acid for $4 \mathrm{~h}$ at $95^{\circ} \mathrm{C}$. The mixture was cooled down and centrifuged for $10 \mathrm{~min}$. The pellet was washed with water three times, and dissolved in $1 \mathrm{ml}$ of $0.5 \mathrm{M}$ $\mathrm{NaOH}$ and the suspension was shaken vigorously overnight at $4^{\circ} \mathrm{C}$ to extract the lignin thioglycolic acid derivatives (LTGAs), and centrifuged for $10 \mathrm{~min}$. The supernatant was collected in a fresh tube, and the pellet was mixed with $0.5 \mathrm{ml}$ of $0.5 \mathrm{M} \mathrm{NaOH}$ for $1 \mathrm{~h}$. Following centrifugation, the supernatant was combined with the previous one, and acidified with $0.3 \mathrm{M}$ concentrated $\mathrm{HCl}$ to precipitate LTGAs at $4^{\circ} \mathrm{C}$ for $4 \mathrm{~h}$. The mixture was centrifuged, and the pellet was kept overnight at $4^{\circ} \mathrm{C}$. The LTGA pellet was dissolved in $1.5 \mathrm{ml}$ of $0 . \mathrm{M} \mathrm{NaOH}$ and the absorption was measured at $280 \mathrm{~nm}$ on a spectrophotometer. Results are reported as the mean of the three replicates.

\section{Statistical analysis}

Statistical analyses of quantitative qRT-PCR data were performed by the GenEx software (MultiD analysis) and JPM9 (SAS Institute Inc, Cary, NC, USA). Bars indicate standard error of three biological replicates at each sampling timepoint. Different letters in different bar differ significantly from the control according to Fit Least Squares (FLS) test, $P \leq 0.05$. CONT (black bar) indicates the untreated plants, TI (shaded) and TII (white) treated with microbial products only once and multiple times, respectively.

\section{Additional files}

Additional file 1: The flavonoid biosynthesis pathway that leads to the production of anthocyanidins and flavonols in Arabidopsis; several transcription factors (MYB, bHLH and WD-40) are indicated along the branches that are likely involved in the transcriptional regulation of the structural genes. The transcription factors are indicated in black box, structural genes in red color and intermediate products in blue color.

Additional file 2: Relative transcript abundance of acetyltranseferase genes (At1g03495, At1g03940, and At3g29590) known to be involved in the acylation (A) UDP-glucosyltransferase (At4g14090 and At5g17030) and GSTs (At1g02920) genes known to be involved in the glycosylation (B), and rhamnose synthesis genes (RHM1, RHM2 and RHM3) involved in the rhamnosylation (C) of flavonoids treated once (TI) and multiple times (TII) with SB in Arabidopsis thaliana. Primers used in these studies, products size for the amplified fragments, accession numbers are shown in Additional file 6. Transcript abundance of each gene was normalized by the level of an actin and EF-1a gene. Bars indicate standard error of three biological replicates at each sampling time-point. For significant level identification, see Figure 1.

Additional file 3: Relative transcript abundance of cinnamyl alcohol dehydrogenase family genes (CAD1, CAD3, CAD4, CAD5, CAD7 and CAD8) known to be involved in lignin biosynthesis treated once (TI) and multiple times (TII) with SB in Arabidopsis thaliana. Primers used in these studies, products size for the amplified fragments, accession numbers are shown in Additional file 6. Transcript abundance of each gene was normalized by the level of an actin and EF-1a gene. Bars indicate standard error of three biological replicates at each sampling time-point. For significant level identification, see Figure 1.

Additional file 4: Relative transcript abundance of laccase (LAC4 and $L A C 17$ ) genes known to be involved in lignin biosynthesis (A) and transcription factors (SND1, MYB58 and MYB63) (B) are known to regulate lignin biosynthesis in Arabidopsis treated once (TI) and multiple times (TII) with SB in Arabidopsis thaliana. Primers used in these studies, products size for the amplified fragments, accession numbers are shown in Additional file 6. Transcript abundance of each gene was normalized by the level of an actin and EF-1a gene. Bars indicate standard error of three biological replicates at each sampling time-point. For significant level identification, see Figure 1.

Additional file 5: Basic chemical properties of Soil Builder used in the present study.

Additional file 6: Primers used for qRT-PCR analysis and expected size for the amplified fragments. The accession number from public database is given below.

\section{Abbreviations}

4CL1: 4-coumarate:CoA ligase1; C3'H1: p-coumarate 3-hydroxylase1; C4H: Cinnamate 4-hydroxylase; CAD: Cinnamyl alcohol dehydrogenase; CCOAOMT: Caffeoyl-CoA O-methyltransferase; COMT1: Caffeic acid Omethyltransferase1; HCT: HydroxycinnamoylCoA: shikimate/ quinatehydroxycinnamyltransferase; CCOAOMT1: Caffeyl COA 3-O-methyltransferase 1; CCR1: Cinnamoyl CoA reductase1; CAD: Cinnamyl alcohol dehydrogenase; PAL: Phenylalanine ammonia-lyase; CHS: Chalcone synthase; CHI: Chalcone isomerase; OUF3GT: UDP-glucose:flavonoid-3-O-

glucosyltransferase; F3H: Flavanone 3-hydroxylase; F3'H: Flavonoid-3'-Ohydroxylase; DFR: Dihydroflavonol-4-reductase; LDOX: Leucoanthocyanidin dioxygenase; UDP-GST: UDP-glucoronosyl/UDP-glucosyltransferase; GST: Glutathione S-transferase; FLS1: Flavonol synthase1; PAP1 \& 2: Production of anthocyanin pigment1 \& 2; EGL3: Enhancer of glabra3; GL3: Glabrous 3; 3G/CT: Flavonoid 3-O-glucosyltransferase; 3RhaT: Flavonol 3-O-rhamnosyltransferase; 7GICT: Flavonol 7-O-glucosyltransferase; 5GICT: Anthocyanin 5-O-glucosyltransferase; PGPR: Plant growth-promoting rhizobacteria; SB: Soil Builder ${ }^{\mathrm{TM}}-\mathrm{AF}$.

\section{Competing interests}

The authors declare that they have no competing interests.

\section{Authors' contributions}

M.B.A. conceived, designed the experiment, collected the sample, performed total RNA extraction, RNA quality, qRT-PCR, analyzed data, sequencing the qRT-PCR products, metabolite analyses, prepared figures and tables and wrote the initial manuscript and finalized the written manuscript. DJM conceived, designed the experiment and contributed to manuscript editing. Both authors read and approved the final manuscript.

\section{Acknowledgements}

This work was supported by the Advanced Microbial Solutions through Rhizosphere Science Laboratory, Department of Plant and Soil Sciences, University of Kentucky, Lexington, KY, USA. We would like to thank UC Davis Genome Center for LC-MSMS data collection and analysis.

Received: 11 March 2013 Accepted: 27 March 2014 Published: 1 April 2014

\section{References}

1. Green RE, Cornell SJ, Scharlemann JPW, Balmford A: Farming and the Fate of Wild Nature. Science 2005, 307(5709):550-555.

2. DeFries $R$, Rosenzweig C: Toward a whole-landscape approach for sustainable land use in the tropics. Proc Natl Acad Sci 2010, 107(46):19627-19632.

3. Barea JM, Pozo MJ, Azcon R, Azcon-Aguilar C: Microbial co-operation in the rhizosphere. J Exp Bot 2005, 56(417):1761-1778.

4. Morgan JA, Bending GD, White PJ: Biological costs and benefits to plantmicrobe interactions in the rhizosphere. J Exp Bot 2005, 56(417):1729-1739. 
5. Adesemoye AO, Torbert HA, Kloepper JW: Plant Growth-Promoting Rhizobacteria Allow Reduced Application Rates of Chemical Fertilizers. Microb Ecol 2009, 58(4):921-929.

6. Morrissey JP, Dow JM, Mark GL, O'Gara F: Are microbes at the root of a solution to world food production? EMBO Rep 2004, 5(10):922-926.

7. Dodd IC, Perez-Alfocea F: Microbial amelioration of crop salinity stress. J Exp Bot 2012, 63(9):3415-3428.

8. Ververidis F, Trantas E, Douglas C, Vollmer G, Kretzschmar G, Panopoulos N: Biotechnology of flavonoids and other phenylpropanoid-derived natural products. Part I: Chemical diversity, impacts on plant biology and human health. Biotechnol J 2007, 2(10):1214-1234.

9. Kutchan TM: A role for intra- and intercellular translocation in natural product biosynthesis. Curr Opin Plant Biol 2005, 8(3):292-300.

10. García-Mediavilla V, Crespo I, Collado PS, Esteller A, Sánchez-Campos S, Tuñón MJ, González-Gallego J: The anti-inflammatory flavones quercetin and kaempferol cause inhibition of inducible nitric oxide synthase, cyclooxygenase- 2 and reactive C-protein, and down-regulation of the nuclear factor kappaB pathway in Chang Liver cells. Eur J Pharmacol 2007, 557(2-3):221-229.

11. Sung PH, Huang FC, Do YY, Huang PL: Functional Expression of Geraniol 10-Hydroxylase Reveals Its Dual Function in the Biosynthesis of Terpenoid and Phenylpropanoid. J Agr Food Chem 2011, 59(9):4637-4643.

12. Ruiz-López N, Sayanova O, Napier JA, Haslam RP: Metabolic engineering of the omega-3 long chain polyunsaturated fatty acid biosynthetic pathway into transgenic plants. J Exp Bot 2012, 63(7):2397-2410.

13. Mandal SM, Chakraborty D, Dey S: Phenolic acids act as signaling molecules in plant-microbe symbioses. Plant Signal Behav 2010, 5(4):359-368.

14. Dixon RA: Natural products and plant disease resistance. Nature 2001, 411(6839):843-847.

15. Jetiyanon K: Defensive-related enzyme response in plants treated with a mixture of Bacillus strains (IN937a and IN937b) against different pathogens. Bio/ Control 2007, 42(2):178-185.

16. Jain A, Singh S, Kumar Sarma B, Bahadur Singh H: Microbial consortium-mediated reprogramming of defence network in pea to enhance tolerance against Sclerotinia sclerotiorum. J Appl Microbiol 2012, 112(3):537-550.

17. Singh A, Sarma BK, Upadhyay RS, Singh HB: Compatible rhizosphere microbes mediated alleviation of biotic stress in chickpea through enhanced antioxidant and phenylpropanoid activities. Microbiol Res 2013, 168(1):33-40.

18. Jones JT, Furlanetto C, Phillips MS: The role of flavonoids produced in response to cyst nematode infection of Arabidopsis thaliana. Nematology 2007, 9:671-677.

19. Winkel-Shirley B: Flavonoid biosynthesis. A colorful model for genetics, biochemistry, cell biology, and biotechnology. Plant Physiol 2001, 126 (2):485-493.

20. Dubos C, Stracke R, Grotewold E, Weisshaar B, Martin C, Lepiniec L: MYB transcription factors in Arabidopsis. Trends Plant Sci 2010, 15(10):573-581.

21. Stracke $R$, Ishihara $H$, Barsch GHA, Mehrtens F, Niehaus K, Weisshaar B: Differential regulation of closely related R2R3-MYB transcription factors controls flavonol accumulation in different parts of the Arabidopsis thaliana seedling. Plant J 2007, 50(4):660-677.

22. Gonzalez A, Zhao M, Leavitt JM, Lloyd AM: Regulation of the anthocyanin biosynthetic pathway by the $\Pi \mathrm{TG} 1 / \mathrm{bHLH} / \mathrm{Myb}$ transcriptional complex in Arabidopsis seedlings. Plant J 2008, 53(5):814-827.

23. Bhuiyan NH, Selvaraj G, Wei Y, King J: Role of lignification in plant defense. Plant Signal Behav 2009, 4(2):158-159.

24. Bhargava A, Mansfield SD, Hall HC, Douglas CJ, Ellis BE: MYB75 Functions in Regulation of Secondary Cell Wall Formation in the Arabidopsis Inflorescence Stem. Plant Physiol 2010, 154(3):1428-1438.

25. Hossain Z, Amyot L, McGarvey B, Gruber M, Jung J, Hannoufa A: The Translation Elongation Factor eEF-1B $\beta 1$ Is Involved in Cell Wall Biosynthesis and Plant Development in Arabidopsis thaliana. Plos One 2012, 7(1):e30425.

26. Zhong R, Demura T, Ye Z-H: SND1, a NAC Domain Transcription Factor, Is a Key Regulator of Secondary Wall Synthesis in Fibers of Arabidopsis. The Plant Cell Online 2006, 18(11):3158-3170.

27. Zhong R, Lee C, Zhou J, McCarthy RL, Ye Z-H: A Battery of Transcription Factors Involved in the Regulation of Secondary Cell Wall Biosynthesis in Arabidopsis. The Plant Cell Online 2008, 20(10):2763-2782.

28. Adesemoye A, Kloepper J: Plant-microbes interactions in enhanced fertilizer-use efficiency. Appl Microbiol Biot 2009, 85(1):1-12.
29. Calvo P, Watts DB, Ames RN, Kloepper JW, Torbert HA: Microbial-Based Inoculants Impact Nitrous Oxide Emissions from an Incubated Soil Medium Containing Urea Fertilizers. J Environ Qual 2013, 42(3):704-712.

30. Bloor SJ, Abrahams S: The structure of the major anthocyanin in Arabidopsis thaliana. Phytochem 2002, 59:343-346.

31. Yonekura-Sakakibara K, Tohge T, Matsuda F, Nakabayashi R, Takayama H, Niida R, Watanabe-Takahashi A, Inoue E, Saito K: Comprehensive Flavonol Profiling and Transcriptome Coexpression Analysis Leading to Decoding Gene-Metabolite Correlations in Arabidopsis. The Plant Cell Online 2008, 20(8):2160-2176

32. Pourcel L, Irani NG, Lu Y, Riedl K, Schwartz S, Grotewold E: The formation of Anthocyanic Vacuolar Inclusions in Arabidopsis thaliana and implications for the sequestration of anthocyanin pigments. Molecular plant 2010, 3(1):78-90.

33. Routaboul J-M, Dubos C, Beck G, Marquis C, Bidzinski P, Loudet O, Lepiniec $L$ : Metabolite profiling and quantitative genetics of natural variation for flavonoids in Arabidopsis. J Exp Bot 2012, 63(10):3749-3764.

34. D'Auria JC: Acyltransferases in plants: a good time to be BAHD. Curr Opin Plant Biol 2006, 9(3):331-340.

35. Skaltsa H, Verykokidou E, Harvala C, Karabourniotis G, Manetasi Y: UV-B protective potential and flavonoid content of leaf hairs of Quercus ilex. Phytochemistry 1994, 37(4):987-990.

36. Báidez AG, Gómez P, Del Río JA, Ortuño A: Dysfunctionality of the Xylem in Olea europaea L. Plants Associated with the Infection Process by Verticillium dahliae Kleb. Role of Phenolic Compounds in Plant Defense Mechanism. J Agr Food Chem 2007, 55(9):3373-3377.

37. Yonekura-Sakakibara K, Tohge T, Niida R, Saito K: Identification of a Flavonol 7-O-Rhamnosyltransferase Gene Determining Flavonoid Pattern in Arabidopsis by Transcriptome Coexpression Analysis and Reverse Genetics. J Biol Chem 2007, 282(20):14932-14941.

38. Matsuda F, Yonekura-Sakakibara K, Niida R, Kuromori T, Shinozaki K, Saito K: MS/MS spectral tag-based annotation of non-targeted profile of plant secondary metabolites. Plant J 2009, 57(3):555-577.

39. Besseau S, Hoffmann L, Geoffroy P, Lapierre C, Pollet B, Legrand M: Flavonoid accumulation in Arabidopsis repressed in lignin synthesis affects auxin transport and plant growth. Plant Cell 2007, 19(1):148-162.

40. Peng M, Hudson D, Schofield A, Tsao R, Yang R, Gu H, Bi Y-M, Rothstein SJ: Adaptation of Arabidopsis to nitrogen limitation involves induction of anthocyanin synthesis which is controlled by the NLA gene. J Exp Bot 2008, 59(11):2933-2944.

41. Tohge T, Nishiyama Y, Hirai MY, Yano M, Nakajima J, Awazuhara M, Inoue E, Takahashi H, Goodenowe DB, Kitayama M, Noji M, Saito K: Functional genomics by integrated analysis of metabolome and transcriptome of Arabidopsis plants over-expressing an MYB transcription factor. Plant J 2005, 42(2):218-235.

42. Zimmermann IM, Heim MA, Weisshaar B, Uhrig JF: Comprehensive identification of Arabidopsis thaliana MYB transcription factors interacting with R/B-like BHLH proteins. Plant J 2004, 40(1):22-34.

43. Pelletier MK, Shirley BW: Analysis of Flavanone 3-Hydroxylase in Arabidopsis Seedlings (Coordinate Regulation with Chalcone Synthase and Chalcone Isomerase). Plant Physiol 1996, 111(1):339-345.

44. Pelletier MK, Murrell JR, Shirley BW: Characterization of Flavonol Synthase and Leucoanthocyanidin Dioxygenase Genes in Arabidopsis (Further Evidence for Differential Regulation of "Early" and "Late" Genes). Plant Physiol 1997, 113(4):1437-1445.

45. Vanholme R, Storme V, Vanholme B, Sundin L, Christensen JH, Goeminne G, Halpin C, Rohde A, Morreel K, Boerjan W: A Systems Biology View of Responses to Lignin Biosynthesis Perturbations in Arabidopsis. The Plant Cell Online 2012, 24(9):3506-3529.

46. Sibout R, Eudes A, Pollet B, Goujon T, Mila I, Granier F, Seguin A, Lapierre C, Jouanin L: Expression pattern of two paralogs encoding cinnamyl alcohol dehydrogenases in Arabidopsis. Isolation and characterization of the corresponding mutants. Plant Physiol 2003, 132(2):848-860.

47. Sibout R, Baucher M, Gatineau M, Van Doorsselaere J, Mila I, Pollet B, Maba B, Pilate G, Lapieffe C, Boerjan W, Jouanin L: Expression of a poplar CDNA encoding a ferulate-5-hydroxylase/coniferaldehyde 5-hydroxylase increases S lignin deposition in Arabidopsis thaliana. Plant Physiol Biochem 2002, 40(12):1087-1096.

48. Sibout R, Eudes A, Mouille G, Pollet B, Lapierre C, Jouanin L, Seguin A: CINNAMYL ALCOHOL DEHYDROGENASE-C and -D are the primary genes involved in lignin biosynthesis in the floral stem of Arabidopsis. Plant Cell 2005, 17(7):2059-2076. 
49. Raes J, Rohde A, Christensen J, Peer Y, Boerjan W: Genome-wide characterization of the lignification toolbox in Arabidopsis. Plant Physiol 2003, 133(3):1051-1071.

50. Lu S, Zhou Y, Li L, Chiang VL: Distinct Roles of Cinnamate 4-hydroxylase Genes in Populus. Plant Cell Physiol 2006, 47(7):905-914.

51. Lee D, Meyer K, Chapple C, Douglas CJ: Antisense Suppression of 4Coumarate:Coenzyme A Ligase Activity in Arabidopsis Leads to Altered Lignin Subunit Composition. The Plant Cell Online 1997, 9(11):1985-1998.

52. Hoffmann L, Besseau S, Geoffroy P, Ritzenthaler C, Meyer D, Lapierre C, Pollet B, Legrand M: Silencing of hydroxycinnamoy-coenzyme A shikimate/quinate hydroxycinnamoyltransferase affects phenylpropanoid biosynthesis. Plant Cell 2004, 16(6):1446-1465.

53. Deluc L, Barrieu F, Marchive C, Lauvergeat V, Decendit A, Richard T, Carde J, Merillon J, Hamdi S: Characterization of a grapevine R2R3-MYB transcription factor that regulates the phenylpropanoid pathway. Plant Physiol 2006, 140(2):499-511.

54. Zhao Q, Dixon RA: Transcriptional networks for lignin biosynthesis: more complex than we thought? Trends Plant Sci 2011, 16(4):227-233.

55. Zhou JL, Lee $\mathrm{CH}$, Zhong RQ, Ye ZH: MYB58 and MYB63 Are Transcriptional Activators of the Lignin Biosynthetic Pathway during Secondary Cell Wall Formation in Arabidopsis. Plant Cell 2009, 21(1):248-266.

56. Derikvand MM, Sierra JB, Ruel K, Pollet B, Do CT, Thevenin J, Buffard D, Jouanin L, Lapierre C: Redirection of the phenylpropanoid pathway to feruloyl malate in Arabidopsis mutants deficient for cinnamoyl-CoA reductase 1. Planta 2008, 227(5):943-956.

57. Tronchet M, Balague C, Kroj T, Jouanin L, Roby D: Cinnamyl alcohol dehydrogenases- $C$ and $D$, key enzymes in lignin biosynthesis, play an essential role in disease resistance in Arabidopsis. Mol Plant Pathol 2010, 11(1):83-92.

58. Eudes A, Pollet B, Sibout R, Do C-T, Séguin A, Lapierre C, Jouanin L: Evidence for a role of AtCAD 1 in lignification of elongating stems of Arabidopsis thaliana. Planta 2006, 225(1):23-39.

59. Oh S, Park S, Han K-H: Transcriptional regulation of secondary growth in Arabidopsis thaliana. J Exp Bot 2003, 54(393):2709-2722.

60. Yonekura-Sakakibara K, Fukushima A, Nakabayashi R, Hanada K, Matsuda F, Sugawara S, Inoue E, Kuromori T, Ito T, Shinozaki K, Wangwattana B, Yamazaki M, Saito K: Two glycosyltransferases involved in anthocyanin modification delineated by transcriptome independent component analysis in Arabidopsis thaliana. Plant J 2012, 69(1):154-167.

61. Gavnholt B, Larsen K: Molecular biology of plant laccases in relation to lignin formation. Physiol Plantarum 2002, 116(3):273-280.

62. Ranocha P, Chabannes M, Chamayou S, Danoun S, Jauneau A, Boudet A-M Goffner D: Laccase Down-Regulation Causes Alterations in Phenolic Metabolism and Cell Wall Structure in Poplar. Plant Physiol 2002, 129(1):145-155.

63. Berthet S, Demont-Caulet N, Pollet B, Bidzinski P, Cezard L, Le Bris P, Borrega N, Herve J, Blondet E, Balzergue S, Lapierre C, Jouanin L: Disruption of LACCASE4 and 17 Results in Tissue-Specific Alterations to Lignification of Arabidopsis thaliana Stems. Plant Cell 2011, 23(3):1124-1137.

64. Zhong R, Lee C, Ye Z-H: Global Analysis of Direct Targets of Secondary Wall NAC Master Switches in Arabidopsis. Mol Plant 2010, 3(6):1087-1103.

65. Yildirim E, Taylor AG, Spittler TD: Ameliorative effects of biological treatments on growth of squash plants under salt stress. Sci Hortic-Amsterdam 2006, 111(1):1-6.

66. Burkett-Cadena M, Kokalis-Burelle N, Lawrence KS, van Santen E, Kloepper JW: Suppressiveness of root-knot nematodes mediated by rhizobacteria. Biol Control 2008, 47(1):55-59.

67. Ali M, Howard S, Chen S, Wang Y, Yu O, Kovacs L, Qiu W: Berry skin development in Norton grape: Distinct patterns of transcriptional regulation and flavonoid biosynthesis. Bmc Plant Biol 2010, 11(1):7.

68. Kleindt CK, Stracke R, Mehrtens F, Weisshaar B: Expression analysis of flavonoid biosynthesis genes during Arabidopsis thaliana silique and seed development with a primary focus on the proanthocyanidin biosynthetic pathway. BMC research notes 2010, 3:255.

69. Mehrtens F, Kranz H, Bednarek P, Weisshaar B: The Arabidopsis transcription factor MYB12 is a flavonol-specific regulator of phenylpropanoid biosynthesis. Plant Physiol 2005, 138(2):1083-1096.

70. Solfanelli C, Poggi A, Loreti E, Alpi A, Perata P: Sucrose-specific induction of the anthocyanin biosynthetic pathway in Arabidopsis. Plant Physiol 2006, 140(2):637-646.
71. Luo J, Nishiyama Y, Fuell C, Taguchi G, Elliott K, Hill L, Tanaka Y, Kitayama M, Yamazaki M, Bailey P, Parr A, Michael AJ, Saito K, Martin C: Convergent evolution in the BAHD family of acyl transferases: identification and characterization of anthocyanin acyl transferases from Arabidopsis thaliana. Plant J 2007, 50(4):678-695.

72. Velten J, Cakir C, Youn E, Chen J, Cazzonelli Cl: Transgene Silencing and Transgene-Derived siRNA Production in Tobacco Plants Homozygous for an Introduced < italic > AtMYB90</italic > Construct. Plos One 2012, 7(2):e30141.

73. Gou J-Y, Felippes FF, Liu C-J, Weigel D, Wang J-W: Negative Regulation of Anthocyanin Biosynthesis in Arabidopsis by a miR156-Targeted SPL Transcription Factor. The Plant Cell Online 2011, 23(4):1512-1522.

74. Qi T, Song S, Ren Q, Wu D, Huang H, Chen Y, Fan M, Peng W, Ren C, Xie D: The Jasmonate-ZIM-Domain Proteins Interact with the WD-Repeat/ bHLH/MYB Complexes to Regulate Jasmonate-Mediated Anthocyanin Accumulation and Trichome Initiation in Arabidopsis thaliana. The Plant Cell Online 2011, 23(5):1795-1814.

75. Sawa S, Demura T, Horiguchi G, Kubo M, Fukuda H: The ATE Genes Are Responsible for Repression of Transdifferentiation into Xylem Cells in Arabidopsis. Plant Physiol 2005, 137(1):141-148.

76. Minic Z, Jamet E, San-Clemente H, Pelletier S, Renou J-P, Rihouey C, Okinyo D, Proux C, Lerouge $P$, Jouanin L: Transcriptomic analysis of Arabidopsis developing stems: a close-up on cell wall genes. BmC Plant Biol 2009, 9(1):6.

77. Huang JL, Gu M, Lai ZB, Fan BF, Shi K, Zhou YH, Yu JQ, Chen ZX: Functional Analysis of the Arabidopsis PAL Gene Family in Plant Growth, Development, and Response to Environmental Stress. Plant Physiol 2010 153(4):1526-1538.

78. Lange BM, Lapierre C, Sandermann H: Elicitor-Induced Spruce Stress Lignin - Structural Similarity to Early Developmental Lignins. Plant Physio/ 1995, 108(3):1277-1287.

doi:10.1186/1471-2229-14-84

Cite this article as: Ali and McNear: Induced transcriptional profiling of phenylpropanoid pathway genes increased flavonoid and lignin content in Arabidopsis leaves in response to microbial products. BMC Plant Biology 2014 14:84.

\section{Submit your next manuscript to BioMed Central and take full advantage of:}

- Convenient online submission

- Thorough peer review

- No space constraints or color figure charges

- Immediate publication on acceptance

- Inclusion in PubMed, CAS, Scopus and Google Scholar

- Research which is freely available for redistribution 